\title{
ANÁLISIS TEXTUAL DE LA NARRATIVA ORAL DE LOS LLANOS COLOMBIANOS: Ejemplo de un informante de Casanare, Colombia ${ }^{1}$
}

\section{COMENTARIOS INTRODUCTORIOS}

En este trabajo se pretende analizar la narrativa oral ${ }^{2}$ presentada por un hablante natural de Casanare, de la zona de los Llanos, una vasta región geográfica que se extiende por Colombia y Venezuela. El motivo que me ha llevado a escoger esta región es, por una parte, personal (el hecho de haber cooperado en una investigación de campo en esta zona durante mis estudios de posgrado y, por ende, el deseo de enfocar el tema de la narrativa oral desde otro punto de vista teniendo en cuenta también el tiempo transcurrido desde que fue hecha la entrevista) y, por otra parte, se debe al hecho de que se trata de una región con una idiosincracia muy específica donde la tradición oral sigue muy viva.

\section{PRESENTACIÓN DE LA REGIÓN ESTUDIADA}

Casanare es uno de los más extensos departamentos de la República de Colombia. Mide $44.490 \mathrm{~km}^{2}$ pero es escasamante poblado (según el censo de 2005 tiene 295.353 habitantes). Se encuentra en la región de los Llanos Orientales Colombianos, en el oriente de Colombia, y consta de 19 municipios. Geográficamente es una zona llana con una altura entre 110 y $230 \mathrm{~m}$ excepto la parte occidental, el Piedemonte llanero, que es montañosa ya que se encuentra en las estribaciones de la cordillera oriental de los Andes que alcanza los $3000 \mathrm{~m}$. El clima es caliente con la temperatura media de 26 a 27 grados centígrados en la zona llana, la región tiene una rica fauna y flora y es bañada de numerosos ríos: Pauto, Meta, Casanare, etc. A pesar de una historia cruel y sangrienta durante la época de la conquista y la colonización y una difícil situación posterior lograron sobrevivir grupos indígenas (achaguas, goahibos, tunebos, salivas...) que hoy día son más de 5.000. La población de la región se dedica principalmente a la agricultura y al ganado excepto en la zona del piedemonte donde hay importantes yacimientos de petróleo con los consecuentes problemas ecológicos.

\footnotetext{
*Dirección de la autora: Filozofska fakulteta, Oddelek za romanske jezike in književnosti, Aškerčeva 2, 1000 Ljubljana, Eslovenia. Correo electrónico: jasmina.markic@ff.uni-lj.si

${ }^{1}$ Para este análisis me he servido de un relato oral, grabado y transcrito durante el trabajo de campo en los Llanos Orientales colombianos en el marco de una investigación sobre la dialectología llevada a cabo durante mis estudios de posgrado en el Seminario Andrés Bello del Instituto Caro y Cuervo (Bogotá, Colombia) en 1986 junto con mis colegas de curso, las profesoras Idalith León O. y Amanda Rey A.

${ }^{2}$ En este artículo no se estudia un aspecto primordial del análisis de textos orales: el fonéticofonológico. Debido a su complejidad y extensión será tema de otro artículo.
} 
El departamento debe su nombre al río Casanare, término derivado probablemente del vocablo indígena achagua, casanari, que significa río de aguas negras. El nombre de su capital Yopal deriva de yopo que en la lengua achagua significa corazón; también es nombre de un árbol maderable 3 .

La zona de los llanos en general, y la zona estudiada en particular, es conocida por sus leyendas, supersticiones, costumbres y su música. José Eustacio Rivera, escritor colombiano, en su novela La vorágine ${ }^{4}$ describe así la región del Casanare:

Casanare no me aterraba con sus espeluznantes leyendas. El instinto de la aventura me impelía a desafiarlas, seguro de que saldría ileso de las pampas libérrimas y de que alguna vez, en desconocidas ciudades, sentiría la nostalgia de los pasados peligros.

(Rivera 1984: 8)

Los llaneros $^{5}$ se desplazan tradicionalmente a caballo o, actualmente, en todoterrenos a través de extensos territorios despoblados con malas carreteras, cuando las hay, inundadas en época de lluvia, donde se encuentran en estrecho contacto con la naturaleza y consigo mismos. No es de extrañar que cuando llegan a una población son muy dados a contar historias, a cantar y bailar. La música y las coplas llaneras provienen del romance español y aun hoy en día se trata a menudo de largos relatos contados o cantados al son de la música sobre las vivencias y faenas

${ }^{3}$ La mayoría de los datos provienen de www.casanare.gov.co consultada en septiembre 2006.

${ }^{4}$ Novela de corte naturalista, considerada una de las más importantes no solo de la literatura colombiana sino de la literatura hispanoamericana, denominada también la gran novela de la selva latinoamericana.

${ }^{5}$ La página oficial del Departamento de Casanare, Colombia (www.casanare.gov.co consultada en septiembre 2006) presenta al llanero de la manera siguiente:

El llanero es de mediana estatura, conformación delgada, trigueño, rasgos ligeramente

finos, ojos negros, cara ovalada, boca mediana, cabello lacio. Siempre se ha identificado con el caballo, porque uno y otro forman una sola naturaleza. Por tradición ha manejado ganados cerriles, se ha dedicado al cultivo de la sementera como medio de subsistencia, cosecha yuca y topocho que junto con la carne son la base de su dieta alimenticia.

El hombre llanero se caracteriza por ser experto nadador y navegante, hábil cazador y pescador, artesano de maderas duras y flexibles, constructor de la arquitectura del caney, vestuario de ropas ligeras, franelas y pantalones cortos llamados guayucos, usa cotizas, sombrero pelo de guama. El dormitorio es de chinchorro de moriche o de cumare.

Para el hombre nativo llanero su vida está en su sabana infinita, en donde se identifica con sus garzas, garrapateros, alcaravanes. Posee gran conocimiento de los animales, sus enfermedades, conoce cada uno de los meses de su apareamiento y cría. Es un fiestero innato, baila, canta y enamora, hace sus grandes parrandos, bebe y es tradicionalista en lo concerniente a celebrar fiestas como la Semana Santa, la fiesta del 29 de Agosto en honor a Santa Rita, el 3 de Mayo día de la Santa Cruz, la Navidad y el año Nuevo. Siempre se le oirá entonando coplas compuestas al amor perdido, a su caballo, a su sabana, cree en Dios, es supersticioso, bastante joven forma su hogar. 
de los llaneros, describiendo el fantástico paisaje, el amor por la mujer llanera, los encuentros con las almas en pena durante sus largos viajes solitarios. El llanero vive en la música y los relatos la identidad autóctona de su pueblo. El típico baile llanero es el joropo que con sus melodía y su zapateo recuerda el flamenco y la zarzuela española. Los instrumentos típicos son la guitarra, el tiple, la bandola, el arpa, el violín, el cuatro, las maracas, la guitarra grande.

\section{EL INFORMANTE Y SU RELATO}

El informante es natural de Trinidad ${ }^{6}$ pero la grabación fue hecha en Yopal ${ }^{7}$. Es un típico llanero en su forma de vivir y en su conservación de las tradiciones de su pueblo. Se ocupa de una finca ganadera y se desplaza frecuentemente desde su finca a otras poblaciones para realizar transacciones comerciales. La región del Casanare es una comunidad lingüística particular: en las cercanías de Boyacá y los Andes existe un dialecto distinto del que se escucha llano adentro. Sin embargo los contactos con el mundo tanto a través de los medios de comuncación, la red, como también a través de los contactos comerciales son causas de que el dialecto se esté perdiendo sobre todo entre los jóvenes que viven en las zonas urbanas, pero llano adentro se mantiene el sociolecto de la zona. La influencia indígena se nota sobre todo en el nivel del léxico y la denominación de los lugares.

El relato analizado se refiere a una bola de fuego que el informante vio en uno de sus viajes y que considera como un alma en pena.

\section{TRANSCRIPCIÓN DEL RELATO «LA BOLA DE FUEGO»}

Una vez er unn ... una vez ibaaa... yo atravesandoo... el Guanapalo, iba pal Duya. Y entonce cuandooo ... iiba en esa travesía ya era ... ibaaa... pasando que pasé el Guanapalo desoué del Guanapalo, que llegué al hato a La Candelaria, me cogió la noche. Y llegando más abajo pues ... ya a las horas de la noche me salió la bola e fuego que llaman la bola e fuego eso uno mira uun... yo miré ue en un tronco corozo ¿sí? Llegó la bola e fuego y ... y se afirmó com un comején. Bueno entonces cuando siguió chispiando que yo miré al comején, pue yo die será una candelilla como se dice una luciérnaga ¿no?. Miré a que alumbraba y que alumbraba, dije seráal algún cocuy, que se llama cocuy un insecto volador ¿sí? que alumbra ... o luciérnaga una con una candelilla que le dici uno. Bueno bien yo pensé en mile de cosa, y cuando me le fui acercando más se me vino pa encima así y entonce yo miree que ... cuando iba, cuando cuando entre más avanzaba más ligero se miba acercando ¿sí? Y miré el chisporroteo de la luz, entoe yo dije ¡Virgen Santísima! ¿Qué será? Claro cuando dije así se me acercó más, se me acercó ma, y ahí fue .... Cuando entonces

\footnotetext{
${ }^{6}$ Trinidad, la región natal del informante, es un municipio rural del departamento de Casanare fundado en 1724, situado a $187 \mathrm{~m}$ de altitud sobre el nivel del mar, con una temperatura promedia de $27^{\circ} \mathrm{C}$. Se encuentra a orillas del río Pauto, mide $2.947 \mathrm{~km}^{2}$ y tiene 11.083 habitantes.

${ }^{7}$ Yopal es la capital del Departamento de Casanare.
} 


\section{ANÁLISIS TEXTUAL DE LA NARRATIVA ORAL DE LOS LLANOS COLOMBIANOS: Ejemplo de un informante de Casanare, Colombia ${ }^{1}$}

\section{COMENTARIOS INTRODUCTORIOS}

En este trabajo se pretende analizar la narrativa oral ${ }^{2}$ presentada por un hablante natural de Casanare, de la zona de los Llanos, una vasta región geográfica que se extiende por Colombia y Venezuela. El motivo que me ha llevado a escoger esta región es, por una parte, personal (el hecho de haber cooperado en una investigación de campo en esta zona durante mis estudios de posgrado y, por ende, el deseo de enfocar el tema de la narrativa oral desde otro punto de vista teniendo en cuenta también el tiempo transcurrido desde que fue hecha la entrevista) y, por otra parte, se debe al hecho de que se trata de una región con una idiosincracia muy específica donde la tradición oral sigue muy viva.

\section{PRESENTACIÓN DE LA REGIÓN ESTUDIADA}

Casanare es uno de los más extensos departamentos de la República de Colombia. Mide $44.490 \mathrm{~km}^{2}$ pero es escasamante poblado (según el censo de 2005 tiene 295.353 habitantes). Se encuentra en la región de los Llanos Orientales Colombianos, en el oriente de Colombia, y consta de 19 municipios. Geográficamente es una zona llana con una altura entre 110 y $230 \mathrm{~m}$ excepto la parte occidental, el Piedemonte llanero, que es montañosa ya que se encuentra en las estribaciones de la cordillera oriental de los Andes que alcanza los $3000 \mathrm{~m}$. El clima es caliente con la temperatura media de 26 a 27 grados centígrados en la zona llana, la región tiene una rica fauna y flora y es bañada de numerosos ríos: Pauto, Meta, Casanare, etc. A pesar de una historia cruel y sangrienta durante la época de la conquista y la colonización y una difícil situación posterior lograron sobrevivir grupos indígenas (achaguas, goahibos, tunebos, salivas...) que hoy día son más de 5.000. La población de la región se dedica principalmente a la agricultura y al ganado excepto en la zona del piedemonte donde hay importantes yacimientos de petróleo con los consecuentes problemas ecológicos.

\footnotetext{
*Dirección de la autora: Filozofska fakulteta, Oddelek za romanske jezike in književnosti, Aškerčeva 2, 1000 Ljubljana, Eslovenia. Correo electrónico: jasmina.markic@ff.uni-lj.si

${ }^{1}$ Para este análisis me he servido de un relato oral, grabado y transcrito durante el trabajo de campo en los Llanos Orientales colombianos en el marco de una investigación sobre la dialectología llevada a cabo durante mis estudios de posgrado en el Seminario Andrés Bello del Instituto Caro y Cuervo (Bogotá, Colombia) en 1986 junto con mis colegas de curso, las profesoras Idalith León O. y Amanda Rey A.

${ }^{2}$ En este artículo no se estudia un aspecto primordial del análisis de textos orales: el fonéticofonológico. Debido a su complejidad y extensión será tema de otro artículo.
} 
El departamento debe su nombre al río Casanare, término derivado probablemente del vocablo indígena achagua, casanari, que significa río de aguas negras. El nombre de su capital Yopal deriva de yopo que en la lengua achagua significa corazón; también es nombre de un árbol maderable 3 .

La zona de los llanos en general, y la zona estudiada en particular, es conocida por sus leyendas, supersticiones, costumbres y su música. José Eustacio Rivera, escritor colombiano, en su novela La vorágine ${ }^{4}$ describe así la región del Casanare:

Casanare no me aterraba con sus espeluznantes leyendas. El instinto de la aventura me impelía a desafiarlas, seguro de que saldría ileso de las pampas libérrimas y de que alguna vez, en desconocidas ciudades, sentiría la nostalgia de los pasados peligros.

(Rivera 1984: 8)

Los llaneros $^{5}$ se desplazan tradicionalmente a caballo o, actualmente, en todoterrenos a través de extensos territorios despoblados con malas carreteras, cuando las hay, inundadas en época de lluvia, donde se encuentran en estrecho contacto con la naturaleza y consigo mismos. No es de extrañar que cuando llegan a una población son muy dados a contar historias, a cantar y bailar. La música y las coplas llaneras provienen del romance español y aun hoy en día se trata a menudo de largos relatos contados o cantados al son de la música sobre las vivencias y faenas

${ }^{3}$ La mayoría de los datos provienen de www.casanare.gov.co consultada en septiembre 2006.

${ }^{4}$ Novela de corte naturalista, considerada una de las más importantes no solo de la literatura colombiana sino de la literatura hispanoamericana, denominada también la gran novela de la selva latinoamericana.

${ }^{5}$ La página oficial del Departamento de Casanare, Colombia (www.casanare.gov.co consultada en septiembre 2006) presenta al llanero de la manera siguiente:

El llanero es de mediana estatura, conformación delgada, trigueño, rasgos ligeramente

finos, ojos negros, cara ovalada, boca mediana, cabello lacio. Siempre se ha identificado con el caballo, porque uno y otro forman una sola naturaleza. Por tradición ha manejado ganados cerriles, se ha dedicado al cultivo de la sementera como medio de subsistencia, cosecha yuca y topocho que junto con la carne son la base de su dieta alimenticia.

El hombre llanero se caracteriza por ser experto nadador y navegante, hábil cazador y pescador, artesano de maderas duras y flexibles, constructor de la arquitectura del caney, vestuario de ropas ligeras, franelas y pantalones cortos llamados guayucos, usa cotizas, sombrero pelo de guama. El dormitorio es de chinchorro de moriche o de cumare.

Para el hombre nativo llanero su vida está en su sabana infinita, en donde se identifica con sus garzas, garrapateros, alcaravanes. Posee gran conocimiento de los animales, sus enfermedades, conoce cada uno de los meses de su apareamiento y cría. Es un fiestero innato, baila, canta y enamora, hace sus grandes parrandos, bebe y es tradicionalista en lo concerniente a celebrar fiestas como la Semana Santa, la fiesta del 29 de Agosto en honor a Santa Rita, el 3 de Mayo día de la Santa Cruz, la Navidad y el año Nuevo. Siempre se le oirá entonando coplas compuestas al amor perdido, a su caballo, a su sabana, cree en Dios, es supersticioso, bastante joven forma su hogar. 
de los llaneros, describiendo el fantástico paisaje, el amor por la mujer llanera, los encuentros con las almas en pena durante sus largos viajes solitarios. El llanero vive en la música y los relatos la identidad autóctona de su pueblo. El típico baile llanero es el joropo que con sus melodía y su zapateo recuerda el flamenco y la zarzuela española. Los instrumentos típicos son la guitarra, el tiple, la bandola, el arpa, el violín, el cuatro, las maracas, la guitarra grande.

\section{EL INFORMANTE Y SU RELATO}

El informante es natural de Trinidad ${ }^{6}$ pero la grabación fue hecha en Yopal ${ }^{7}$. Es un típico llanero en su forma de vivir y en su conservación de las tradiciones de su pueblo. Se ocupa de una finca ganadera y se desplaza frecuentemente desde su finca a otras poblaciones para realizar transacciones comerciales. La región del Casanare es una comunidad lingüística particular: en las cercanías de Boyacá y los Andes existe un dialecto distinto del que se escucha llano adentro. Sin embargo los contactos con el mundo tanto a través de los medios de comuncación, la red, como también a través de los contactos comerciales son causas de que el dialecto se esté perdiendo sobre todo entre los jóvenes que viven en las zonas urbanas, pero llano adentro se mantiene el sociolecto de la zona. La influencia indígena se nota sobre todo en el nivel del léxico y la denominación de los lugares.

El relato analizado se refiere a una bola de fuego que el informante vio en uno de sus viajes y que considera como un alma en pena.

\section{TRANSCRIPCIÓN DEL RELATO «LA BOLA DE FUEGO»}

Una vez er unn ... una vez ibaaa... yo atravesandoo... el Guanapalo, iba pal Duya. Y entonce cuandooo ... iiba en esa travesía ya era ... ibaaa... pasando que pasé el Guanapalo desoué del Guanapalo, que llegué al hato a La Candelaria, me cogió la noche. Y llegando más abajo pues ... ya a las horas de la noche me salió la bola e fuego que llaman la bola e fuego eso uno mira uun... yo miré ue en un tronco corozo ¿sí? Llegó la bola e fuego y ... y se afirmó com un comején. Bueno entonces cuando siguió chispiando que yo miré al comején, pue yo die será una candelilla como se dice una luciérnaga ¿no?. Miré a que alumbraba y que alumbraba, dije seráal algún cocuy, que se llama cocuy un insecto volador ¿sí? que alumbra ... o luciérnaga una con una candelilla que le dici uno. Bueno bien yo pensé en mile de cosa, y cuando me le fui acercando más se me vino pa encima así y entonce yo miree que ... cuando iba, cuando cuando entre más avanzaba más ligero se miba acercando ¿sí? Y miré el chisporroteo de la luz, entoe yo dije ¡Virgen Santísima! ¿Qué será? Claro cuando dije así se me acercó más, se me acercó ma, y ahí fue .... Cuando entonces

\footnotetext{
${ }^{6}$ Trinidad, la región natal del informante, es un municipio rural del departamento de Casanare fundado en 1724, situado a $187 \mathrm{~m}$ de altitud sobre el nivel del mar, con una temperatura promedia de $27^{\circ} \mathrm{C}$. Se encuentra a orillas del río Pauto, mide $2.947 \mathrm{~km}^{2}$ y tiene 11.083 habitantes.

${ }^{7}$ Yopal es la capital del Departamento de Casanare.
} 
unoparejar palejar labola e fuego entoes le toca maldecirla ¿sí? maldecirla, decirle palabra soece, groseras así ¿se entiende? YY se fue, yo no supe má, se alejó, yo ... se me perdió.

Eso sí es un alma en pena, porqueee... dicen según la leyenda ¿no? quee.. que fue quee ... quee una mama estuvo con tenía una hija ¿sí? y ella all al matarla yo no sé cómo fue, yo no me sé bien la historia sí perooo ... pero más o menos hago un recuento de lo que más o meno he oído ¿sí?

Cuando... ella salió, la hija ... mató a la mamá, y a la misma mamá le metió candela al ... a la casa donde estaba ella ¿sí? Y entuens entonces al tiempo de morir ella, la maldijo, que sería bola e fuego para toa la vida, entoes así quedó la historia.

\section{ANÁLISIS DEL TEXTO}

El texto es narrado por un narrador (el informante / hablante) en una situación de entrevista, va dirigido a un grupo de personas y se refiere a acontecimientos del pasado. El narrador sigue presente durante todo el relato y lo señala mediante el uso de la primera persona del singular (p.ej.: una vez ibaaa... yo atravesandoo; cuando siguió chispiando que yo miré al comején, pue yo die será una candelilla; etc.), ya que narra hechos que le ocurrieron personalmente, y que repite muchas veces. El narrador y el protagonista se confunden en el relato principal. El uso enfático del yo (p. ej.: Bueno bien yo pensé en mile de cosa...; entonce yo miree que...; entoe yo dije ...) se podría explicar con el deseo del narrador de convencer a su público de que lo narrado le había ocurrido de verdad, que él realmente había vivido los hechos relatados. Mantiene contacto permanente con sus oyentes intercalando elementos que exigen la confirmación de los oyentes (¿sí?, ¿no?, ¿se entiende?) y desempeñan el papel del mantenimiento de la atención interlocutiva. Usa el estilo indirecto libre (Reyes 230-231:1984) al plantearse preguntas retóricas en medio de la narración (yo die será una candelilla como se dice una luciérnaga ¿no?; ¡Virgen Santísima! ¿Qué será?) y se refiere a lo que la gente dice o a leyendas que corroboran el relato de lo acontecido (... palejar labola e fuego entoes le toca maldecirla isí?; porqueee... dicen según la leyenda ¿no? quee.. ). Dentro del mismo relato tiende a explicar los términos como cocuy o luciérnaga para convencerse que el público le entiende, manteniendo así contacto permanente con los interlocutores (... que se llama cocuy un insecto volador ¿sí? que alumbra ... o luciérnaga una con una candelilla que le dici uno...).

El funcionamiento de los tiempos verbales en la narración no corresponde siempre a los valores llamados habituales o básicos que se refieren al momento de la narración o a un punto de referencia alternativo, sino que tienen valores pragmáticos que desempeñan una función en la organización del discurso narrativo (Fleischman 1985: 852). Así los cambios del presente al pasado y vice versa en el relato analizado señalan el traslado del tiempo y espacio del relato al momento de la narración, el continuo vaivén entre lo narrado y la manera y el momento de narrar, entre el narrador y el protagonista ya que el narrador adopta las categorías temporales y espaciales del protagonista (Reyes 1984: 84). En las incursiones del narrador en su propio relato, en el mantenimiento de contacto con los oyentes, en los fragmentos que corresponden al estilo indirecto libre las acciones se presentan 
unoparejar palejar labola e fuego entoes le toca maldecirla ¿sí? maldecirla, decirle palabra soece, groseras así ¿se entiende? YY se fue, yo no supe má, se alejó, yo ... se me perdió.

Eso sí es un alma en pena, porqueee... dicen según la leyenda ¿no? quee.. que fue quee ... quee una mama estuvo con tenía una hija ¿sí? y ella all al matarla yo no sé cómo fue, yo no me sé bien la historia sí perooo ... pero más o menos hago un recuento de lo que más o meno he oído ¿sí?

Cuando... ella salió, la hija ... mató a la mamá, y a la misma mamá le metió candela al ... a la casa donde estaba ella ¿sí? Y entuens entonces al tiempo de morir ella, la maldijo, que sería bola e fuego para toa la vida, entoes así quedó la historia.

\section{ANÁLISIS DEL TEXTO}

El texto es narrado por un narrador (el informante / hablante) en una situación de entrevista, va dirigido a un grupo de personas y se refiere a acontecimientos del pasado. El narrador sigue presente durante todo el relato y lo señala mediante el uso de la primera persona del singular (p.ej.: una vez ibaaa... yo atravesandoo; cuando siguió chispiando que yo miré al comején, pue yo die será una candelilla; etc.), ya que narra hechos que le ocurrieron personalmente, y que repite muchas veces. El narrador y el protagonista se confunden en el relato principal. El uso enfático del yo (p. ej.: Bueno bien yo pensé en mile de cosa...; entonce yo miree que...; entoe yo dije ...) se podría explicar con el deseo del narrador de convencer a su público de que lo narrado le había ocurrido de verdad, que él realmente había vivido los hechos relatados. Mantiene contacto permanente con sus oyentes intercalando elementos que exigen la confirmación de los oyentes (¿sí?, ¿no?, ¿se entiende?) y desempeñan el papel del mantenimiento de la atención interlocutiva. Usa el estilo indirecto libre (Reyes 230-231:1984) al plantearse preguntas retóricas en medio de la narración (yo die será una candelilla como se dice una luciérnaga ¿no?; ¡Virgen Santísima! ¿Qué será?) y se refiere a lo que la gente dice o a leyendas que corroboran el relato de lo acontecido (... palejar labola e fuego entoes le toca maldecirla isí?; porqueee... dicen según la leyenda ¿no? quee.. ). Dentro del mismo relato tiende a explicar los términos como cocuy o luciérnaga para convencerse que el público le entiende, manteniendo así contacto permanente con los interlocutores (... que se llama cocuy un insecto volador ¿sí? que alumbra ... o luciérnaga una con una candelilla que le dici uno...).

El funcionamiento de los tiempos verbales en la narración no corresponde siempre a los valores llamados habituales o básicos que se refieren al momento de la narración o a un punto de referencia alternativo, sino que tienen valores pragmáticos que desempeñan una función en la organización del discurso narrativo (Fleischman 1985: 852). Así los cambios del presente al pasado y vice versa en el relato analizado señalan el traslado del tiempo y espacio del relato al momento de la narración, el continuo vaivén entre lo narrado y la manera y el momento de narrar, entre el narrador y el protagonista ya que el narrador adopta las categorías temporales y espaciales del protagonista (Reyes 1984: 84). En las incursiones del narrador en su propio relato, en el mantenimiento de contacto con los oyentes, en los fragmentos que corresponden al estilo indirecto libre las acciones se presentan 
en presente de indicativo, en muchos casos en su valor atemporal (p. ej.: la bola e fuego que llaman la bola e fuego; dije seráal algún cocuy, que se llama cocuy un insecto volador isí?) y en los tiempos verbales de la esfera del presente.

El narrador emplea los tiempos verbales de la esfera del pasado cuando narra su relato, ya que se trata de una narración de un acontecimiento que tuvo lugar en el pasado. En el relato predominan el pretérito imperfecto y el pretérito perfecto simple, dos tiempos verbales de la narración que marcan el tiempo anterior al momento de la narración (pasado) y se oponen por su valor aspectual. El imperfecto es un tiempo verbal «indefinido», abierto, sin límites que enmarquen la acción ni en su inicio ni en su fin, se usa para la descripción, la indicación de las circunstancias, para presentar el escenario donde se desarrollan otras acciones. El pretérito perfecto simple señala un período de tiempo definido por el contexto o por expresiones de tiempo y expresa acciones terminadas, señala acciones que se suceden y "aceleran" la narración.

La narración se abre con la fórmula clásica de los cuentos «Una vez er unn ... una vez ibaaa ...». El hablante nos sitúa en medio de la narración con una perífrasis verbal en imperfecto, que se repite y acentúa el progresar de la acción (en este caso el viaje del protagonista). Ubica los acontecimientos y sitúa a los oyentes en un marco temporal, el pasado, definido vagamente por «una vez», y el espacio, definido geográficamente: el río Guanapalo y la población del Duya hacia donde se dirigía el narrador/protagonista después de atravesar el Guanapalo (Una vez er unn ... una vez ibaaa... yo atravesandoo... el Guanapalo, iba pal Duya..). Lo indica primero en imperfecto, situándose aún en el marco de las circunstancias que preparan los acontecimientos, y lo repite en pretérito perfecto simple llevando de esa manera a los oyentes hacia acciones que provocan un cambio de perspectiva: ... ibaaa... pasando que pasé el Guanapalo desoué del Guanapalo, que llegué al hato a La Candelaria, me cogió la noche. Sigue una serie de acciones narradas en pretérito perfecto simple: el paso del Guanapalo, la caída de la noche y la llegada al hato (finca ganadera) de la Candelaria, pero antes de llegar al hato lo alcanzó la noche y apareció la bola de fuego. El imperfecto tiene aquí la función de cambiar de enfoque, como si se tratara de una cámara que acerca o aleja los acontecimientos, y de desacelerar la acción. El narrador interviene y se pregunta varias veces cuál es ese fenómeno extraño (usa el futuro imperfecto para expresar la probabilidad), emplea el estilo indirecto libre (dije seráal algún cocuy, que se llama cocuy un insecto volador ¿sí? que alumbra ...) utilizando los tiempos verbales de la esfera del presente. El cambio de enfoque se hace mediante el cambio de los tiempos verbales, el pretérito perfecto simple y el imperfecto (Miré a que alumbraba y que alumbraba ...). Además, con el imperfecto se acentúa la duración de la acción suspendiéndola en el tiempo. Los acontecimientos que siguen se indican en pretérito perfecto simple (... yo pensé en mile de cosa, y cuando me le fui acercando más se me vino pa encima así y entonce yo miree que...) y vuelven a interrumpirse con el cambio de enfoque en imperfecto (cuando iba, cuando cuando entre más avanzaba más ligero se miba acercando). El clímax del relato narrado es justamente cuando la bola de fuego se le viene encima. 
En ese momento de la narración aparecen, como ya queda señalado arriba, varios cambios de enfoque del narrador. El presente de indicativo señala verdades generales, el conocimiento del mundo (en este caso cómo hay que proceder para espantar las bolas de fuego según las creencias de los habitantes del llano).Termina esta parte del discurso con el enfoque aspectual perfectivo, con el pretérito perfecto simple que señala el término de la acción, el final del relato: YY se fue, yo no supe má, se alejó, yo ... se me perdió.

El narrador vuelve a trasladarse al momento de la narración y con el presente de indicativo indica una creencia de los llaneros (una «verdad general») de que las bolas de fuego son generalmente almas en pena. En ese momento, para apoyar su afirmación, el narrador introduce el relato de otro narrador, es decir, una cita (Reyes 1984: 42). Lo manifiesta explícitamente citando una afirmación ajena marcando su condición de retransmisor: «yo no me sé bien la historia sí perooo... pero más o menos hago un recuento de lo que más o meno he oído ¿sí?». Como se trata de una leyenda que no recuerda exactamente vacila al contarla y pone la afirmación bajo la responsabilidad de otro enunciador no definido. Los acontecimientos (el asesinato de la madre por parte de su hija y la maldición de esta antes de morir) se cuentan de nuevo en los tiempos de la esfera del pasado: el pretérito perfecto simple para acciones sucesivas del pasado, un imperfecto que señala la circunstancia y un condicional simple para marcar una acción posterior (Cuando... ella salió, la hija ... mató a la mamá, y a la misma mamá le metió candela al ... a la casa donde estaba ella ¿sí? Y entuens entonces al tiempo de morir ella, la maldijo, que sería bola e fuego para toa la vida...).

El texto podría ser definido como un texto narrado en el sentido de ser una secuencia que tiene como objetivo contar algo. El narrador narra un suceso, un hecho situado en otro espacio / tiempo diferente del suyo. Sin embargo, algunos elementos como la presencia del yo, el hecho de dirigirse a los oyentes, de mantener el contacto, el uso tanto del imperfecto como del pretérito perfecto simple y del presente general o gnómico hacen pensar en fragmentos dialógicos y monológicos.

Dos de las propiedades esenciales del texto en general son la coherencia, «que regula la posibilidad de que sean accesibles entre sí e interactúen de un modo relevante los componentes del mundo textual, es decir, la configuración de los conceptos y de las relaciones que subyacen bajo la superficie del texto» (Beaugrande, Dressler 1997: 37), y la cohesión, que «establece las diferentes posibilidades en que pueden conectarse entre sí dentro de una secuencia los componentes de la superficie textual, es decir, las palabras que realmente se escuchan o se leen» (ibid 1997:35). Por lo tanto, para la construcción de un texto son importantes no sólo la competencia idiomática del hablante sino también lo que se denomina competencia pragmática o competencia comunicativa. El texto narrado se comprende perfectamente, las ideas se entrelazan y se siguen lógicamente. Se puede afirmar que el relato es coherente y cohesivo. El narrador introduce el relato con una fórmula discursiva usada en los cuentos, desarrolla el relato que alcanza su clímax y lo concluye introduciendo otro relato dentro del relato principal como explicación y conclusión del primero. 
En el texto estudiado los principales procedimientos de la cohesión textual son la recurrencia, el uso de los marcadores discursivos, la expresión de las relaciones temporales y aspectuales. La recurrencia o repetición de un elemento del texto en el texto mismo es un procedimiento muy frecuente en el texto oral analizado. Las repeticiones al inicio como «Una vez er unn ... una vez ibaaa... yo atravesandoo... el Guanapalo, iba pal Duya. Y entonce cuandooo ... iiba en esa travesía ya era ... ibaaa... pasando... " señalan que nos encontramos frente a un texto oral: las vacilaciones inciales del hablante le ayudan a entrar en confianza. Las repeticiones dentro del texto como "quee.. que fue quee ... quee», "Miré a que alumbraba y que alumbraba", marcan en ese caso el deseo de establecer las relaciones con lo dicho anteriormente. También las sustituciones, las paráfrasis son elementos de la cohesión y elementos que establecen y mantienen el contacto con el público y tienen, además del valor fático (la repetición de ¿no?, ¿sí?), cierto valor metalingüístico (Jakobson 1988:37): «será una candelilla como se dice una luciérnaga ¿no?. Miré a que alumbraba y que alumbraba, dije seráal algún cocuy, que se llama cocuy un insecto volador isí? que alumbra ... o luciérnaga una con una candelilla que le dici uno.. «.

El narrador emplea algunos marcadores discursivos ${ }^{8}$ que también se repiten en el relato. El marcador $y$ entonces ( $Y$ entonces; $Y$ entuens entonces) le permite mantener o volver a la línea discursiva y, al mismo tiempo, mantener la atención interlocutiva. Los marcadores bueno entonces (Bueno entonces cuando siguió chispiando que yo miré al comején, pue yo die será una candelilla como se dice una luciérnaga ¿no?. ) y bueno bien (Bueno bien yo pensé en mile de cosa...) indican la continuación, pues marcan la consecuencia, enlazan ideas de diferentes partes del discurso o simplemente sirven de muletilla. La conjunción y también desempeña la función de marcador de discurso, sirve para vincular los miembros del discurso con significados diferentes o también como muletilla (Y llegando más abajo...; Y miré el chisporroteo de la luz...; Y entuens entonces al tiempo de morir ella,...; YY se fue, yo no supe má,...).

Como se ha visto más arriba el narrador usa los tiempos verbales como elementos de cohesión y coherencia del texto. Prevalecen los dos tiempos verbales de la narración en el pasado: el pretérito perfecto simple y el pretérito imperfecto de indicativo. Ambos se refieren al pasado pero difieren en la expresión aspectual de la acción. El pretérito perfecto simple sirve para indicar acciones perfectivas. El imperfecto marca el cambio de enfoque y el pasado en transcurso. Las perífrasis verbales en el texto añaden valores temporales y aspectuales y contribuyen a una mayor expresividad. "Ibaaa... yo atravesandoo...» acentúa la progresividad en el pasado y el aspecto no terminado; «siguió chispiando» indica la fase media de la acción, la continuidad de la acción, pero esa continuidad es vista como terminada, la acción es perfectiva (el auxiliar seguir está en pretérito perfecto simple). Con «me

\footnotetext{
8 »Los marcadores discursivos son unidades lingüísticas invariables que no ejercen una función sintáctica en el marco de la predicación oracional y poseen un cometido coincidente en el discurso: el de guiar, de acuerdo con sus distintas propiedades morfosintácticas, semánticas y pragmáticas, las inferencias que se realizan en la comunicación« (Portolés 2001:25).
} 
le fui acercando» el narrador ve la acción como terminada pero durativa y progresiva (el auxiliar ir esta en pretérito perfecto simple). En «entonce yo miree que ... cuando iba, cuando cuando entre más avanzaba más ligero se miba acercando» el narrador usa la misma perífrasis verbal pero con un enfoque aspectual diferente de acción durativa progresiva e imperfectiva (el auxiliar ir está en imperfecto).

El narrador concluye su relato sobre su experiencia personal con la bola de fuego $y$ el relato sobre el relato (la leyenda del matricidio) con marcadores conclusivos: $y$ recurrente (YY se fue, yo no supe má, se alejó, yo ... se me perdió), entonces ( ... entoes así quedó la historia.).

\section{CONCLUSIONES}

El relato Bola de Fuego contiene un relato dentro del relato. Consta, por una parte, de la narración de una experiencia propia (encuentro con la bola de fuego), y por otra parte de la narración del origen de una leyenda (matricidio). En el primer relato el narrador es el mismo hablante que participa como protagonista (se identifican hablante, narrador y protagonista), la narración está en primera persona. E1 narrador-hablante asume una actitud muy segura, salvo al comienzo donde todavía hay vacilaciones iniciales. En el segundo relato el narrador no participa activamente, su única intervención es para expresar su inseguridad en cuanto a lo que dice la gente y la leyenda. El mundo conceptual en el relato Bola de Fuego (los dos relatos conforman uno solo) se organiza alrededor de los valores espirituales que proceden del medio social al que pertenece el narrador. Se destaca la creencia en la existencia de lo sobrenatural. La noche es un momento propicio para las apariciones, crímenes, maldiciones, conjuros y castigos. La Bola de Fuego destaca el elemento supersticioso de la cultura llanera. La travesía nocturna y solitaria del informante revela un aspecto típico de la vida del llanero. La extensión de la región y sus actividades de ganadero le obligan a hacer largos recorridos a caballo de día y de noche, circunstancia propicia para que la realidad se vuelva ficción. E1 hablante/informante está inmerso en el mundo de las tradiciones y costumbres de su pueblo que mantiene muy viva la tradición oral y la actitud creadora ya que es muy frecuente la producción de poemas, relatos y cantos. 


\section{Bibliografía}

BeAugrande y Dressler (1997) Introducción a la lingüística del texto. (Versión española y estudio preliminar de Sebastián Bonilla). Barcelona: Ariel

Casado Velarde, Manuel (1993) Introducción a la gramática del texto del español. Madrid: Arco/Libros.

Fernández De CASTRo, Félix (1999) Las perifrasis verbales en el español actual. Madrid: Gredos.

FleIsCHMAN, Suzanne (1985) «Discourse functions of tense-aspect oppositions in narrative: toward a theory of grounding.» Linguistics 23, 851-882.

Fleischman, Suzanne (1990) Tense and Narrativity. London: Routledge.

Fuentes Rodríguez, Catalina (2000) Lingüística pragmática y análisis del discurso. Madrid: ArcoLibros

García Fernández, Luis (2006) Diccionario de Perífrasis Verbales. Madrid: Gredos

Gómez Torrego, Leonardo (1970) «La estilística en las perífrasis verbales.» En Homenaje universitario a Dámaso Alonso. Madrid: Gredos, 85-96.

Gómez Torrego, Leonardo (1988) Perífrasis verbales. Sintaxis, semántica y estilística.

JAKOBSON, Roman (1988) Lingüistica y poética. (Traducción de Ana María Gutiérrez Cabello). Madrid: Cátedra

LEÓN, Idalith/Jasmina MARKIČ/Amanda REY (1986) La tradición oral en los Llanos Orientales. Bogotá: ICC. [Inédito.]

MARKIČ, Jasmina (1990) «Sobre las perífrasis verbales en español.» Linguistica XXX, 169-206. Montes Giraldo, José (1985) Estudios sobre el español de Colombia. Bogotá: ICC.

PorTOLÉs, José (2001) Los marcadores del discurso. Barcelona: Ariel

REYes, Graciela (1984) Polifonía Textual. Madrid: Gredos.

REYES, Graciela (1990) «Valores estilísticos del imperfecto.» RFE, tomo LXX, fasc. 1-2. Madrid: CSIC, 45-70.

RIVERA, José Eustacio (1984) La vorágine. Bogotá: Oveja Negra

SILvA-CoRvalÁN, Carmen (1987) «La narración oral española: estructura y significado » En: Enrique Bernárdez (ed.), Lingüística del texto. Madrid: Arco Libros, 265-292.

www.casanare.gov.co (consultado el 17.9.2006) 


\section{Povzetek \\ BESEDILNA ANALIZA USTNE PRIPOVEDI KOLUMBIJSKIH LLANEROSOV: \\ Primer informanta iz departmaja Casanare}

Članek se ukvarja z analizo narativnih besedil pri ustnem izročilu kolumbijskih llanerosov, prebivalcev področja Llanosov, obširnih nižin, ki se razprostirajo v Kolumbiji in Venezueli. Njihove pripovedi in pesmi temeljijo na starih ljudskih izročilih in legendah, značilnih za to prostrano in samotno področje, kjer naselja med seboj ločijo na stotine kilometrov brezpotja. Pri analizi narativnih prvin v pesmih in pripovedih so posebno poudarjene tiste, s katerimi se izražata časovnost in aspektualnost: raba glagolskih paradigem in glagolskih perifraz. Analiza besedila se osredotoča tudi na druge značilnosti ustnega narativnega besedila, kot so deiktični elementi in povezovalci, ter poskuša osvetliti besedilne postopke, ki ustvarjajo koherentnost ustnega diskurza. Analiza omenjenega besedila osvetljuje tudi nekatere oblikoslovnoskladenjske in leksikalne značilnosti tako imenovane ameriške španščine. 